\title{
Variations of Vitamin D in Various Stages of Breast Carcinoma: A Randomized Case Control Study
}

\section{Aananda Krishna KS ${ }^{1 *}$, Saai Ram Thejas ${ }^{2}$, Aniruddhan $\mathrm{VJ}^{1}$ and Sudarsan Adithya ${ }^{1}$}

${ }^{1}$ Medipoint Polyclinic, Secunderabad, Telangana, India

${ }^{2}$ RVM Institute of Medical Sciences, Siddipet, Telangana, India

*Corresponding Author: Aananda Krishna KS, Medipoint Polyclinic, Secunderabad, Telangana, India.
Received: October 19, 2021

Published: November 16, 2021

(C) All rights are reserved by Aananda

Krishna KS., et al.

\section{Abstract}

The study aimed to find the diagnostic significance of serum Vitamin D in various stages of Breast Carcinoma. Epidemiological studies state an increase in the incidence of breast cancer and are one of the commonest forms of cancer linked to mortality in women. Unfortunately, despite Maximum treatment, results are not satisfactory, and survival rates are found to diminish. So it is being arrived that new approaches are needed in understanding and treating Breast Carcinoma.

Design/Methods: People with Breast Carcinoma were selected to be part of the study after taking adequate consent. We have attempted to illustrate that Vitamin D levels in the serum can very much aid in monitoring various stages of Breast Carcinoma.

Results: The Vitamin D serum level was significantly decreasing in various progressing stages of breast carcinoma compared to their control.

Conclusion: Vitamin D is a hormone with heterogenic action. Therefore, its levels in breast carcinoma patients are inversely proportionate with progression of Breast Carcinoma.

Keywords: Vitamin D; Breast Carcinoma

\section{Introduction}

Cancer is a disease with a broader spectrum affecting almost all body organs by inducing metaplasia and loss of control over normal cell cycle division resulting in extensive growth of tissue that metastasizes to various parts. This loss over cell cycle control ultimately leads to loss of organ function, which almost invariably results in the individual's death. The etiology of the cancer is so complex that it may arise from a simple environmental cause to a complex hereditary factor, which results in a variety of cancer at different places of the body with varying prognostic values.

Malignancy is defined as the transmission of malignant phenotype from the parent cell to the daughter cell. This implies that the DNA is the source of the underlying malignant lesion. Multiple irreversible mutations in genes essential for cell development can cause cancer [1]. Because the DNA repair network is so crucial for the genome's integrity, its loss, whether inherited or acquired, is harmful and can lead to increased genomic instability, leading to cancer. Although mammalian cells have a robust DNA repair and free radical scavenging system, specific DNA lesions caused by intrinsic and extrinsic mutagenesis may likely evade these DNA "monitoring" mechanisms and represent an early step in human carcinogenesis [2].

A wide range of physical, chemical, and viral factors can cause accelerated cell division and eventually neoplastic transformation. The activation or changed expression of proto-oncogenes to oncogenes and the deletion or inactivation of tumor suppressor genes, 
which govern regular cellular activity, appear to be involved in forming entirely malignant tumors.

The persisting magnitude of the carcinoma issue, as well as the failure of conventional advanced invasive disease chemotherapy to achieve significant reductions in mortality rates for common cancers such as lung, colon, breast, prostate, and pancreas cancers, indicate that new approaches to cancer control and treatment are urgently needed.

Breast Cancer's aetiology, diagnosis, and treatment have all been connected to a variety of causes. Vitamin D, has been identified to play an important role in cancer cells. Vitamin D receptors are found in breast tissue, and vitamin D can bind to them, reducing oncogenesis, carcinogenesis, and metastasis in the cell. As a result, vitamin $\mathrm{D}$ is thought to help guard against breast cancer by making breast cells intelligent $[3,4]$.

A conventional study conducted in the United States found that calcium-only and calcium + vitamin D categories had reduced cancer rates than the placebo pill group after 4 years. Higher vitamin D levels were linked to a decreased risk of cancer in women [5]. Vitamin D levels in postmenopausal women were shown to have a 12 per cent lower risk of breast cancer than postmenopausal women with low vitamin D levels [6]. A conventional study conducted in Canada in 2009 found that women with low vitamin D levels were nearly twice as likely as women with high vitamin D levels to have their cancer spread to another part of the body [7]. In addition, women with low vitamin D levels had larger tumours than women with high vitamin D levels, according to a traditional study conducted in Belgium in 2012 [8].

This has triggered the interest to study the level of vitamin D in breast cancer. However, such data for the Indian population was found to be lagging. Hence, this study is aimed to assess the level of vitamin $d$ (1;25 dihydroxy cholecalciferol) in the breast cancer patient.

\section{Materials and Methods}

\section{Methodology}

$2 \mathrm{ml}$ of blood is taken from the collected $5 \mathrm{ml}$ of blood and centrifuged. The serum obtained is analyzed by electrochemiluminescence by 2010 Roche for Serum Vitamin D level.
Experimental design

Study Method - Randomised Case-control study

74 Participants were included in the study, after getting consent from the participants' blood samples were collected, and serum Vitamin D levels were found. The participants were taken up into the study based on inclusion and exclusion criteria.

Inclusion criteria

- $\quad$ Patient diagnosed with breast cancer.

- $\quad$ Age-matched controls who do not have any vitamin D disorder.

Exclusion criteria

- $\quad$ Patients having chronic Skin diseases.

- $\quad$ Patients having Gastrointestinal chronic diseases.

- $\quad$ Patients taking MultiVitamin supplements.

Totally 76 participants were initially taken into the study, and 2 participants from the control group dropped out voluntarily from the study, so the study population had 38 participants in the case group and 36 participants in the control group. This study's Breast Cancer patients were staged according to American Joint Committee on Cancer staging for comparative and statistical significance and SPSS significance analysis.

Group-I: Normal subjects, Group-II: Stage-0 Breast Carcinoma (Carcinoma Insitu), Group-III: Stage-I Breast Carcinoma, Group-IV: Stage-II Breast Carcinoma, Group-V: Stage III Breast Carcinoma and Group-VI: Stage IV Breast Carcinoma patients. Patients demographic data, including sex, age, and risk factors for cancer events, including a family history of breast cancer, histopathological records, were recorded.

The study was conducted from 2015 to 2016 in a Rural Hospital in Tamil Nadu, India.

\section{Statistical analysis}

The SPSS software application, version 17.0, was used to analyze the data (SPSS Inc., Chicago, Illinois, USA). Range, mean, SD, and median were used to represent quantitative data, whereas fre- 
quency and percentage were used to express qualitative data. At 0.05 , the P-value was judged to be statistically significant.

\section{Results}

\section{Study participants}

The demographics, histological cell type, and Stage of Breast Carcinoma of the 38 patients, which included $11,6,9,9$, and 3 , were Stage 0, Stage I, Stage II, Stage III, and Stage IV, respectively.

\begin{tabular}{|l|c|c|c|}
\hline \multicolumn{1}{|c|}{ Particulars } & Control & $\begin{array}{c}\text { Case-Breast } \\
\text { Carcinoma } \\
\text { Patients }\end{array}$ & P valve \\
\hline $\begin{array}{l}\text { Number of } \\
\text { participants }\end{array}$ & 36 & 38 & \\
\hline $\begin{array}{l}\text { Percentage of } \\
\text { participants }\end{array}$ & $48.6 \%$ & $52.4 \%$ & \\
\hline 25(OH)D & $36.59 \pm 6.78$ & $21.10 \pm 8.25$ & $0.000^{* a, b}$ \\
\hline
\end{tabular}

Table 1: Comparison of serum Vitamin D between control and case population.

\begin{tabular}{|l|c|c|c|c|c|c|}
\hline Particulars & Control & $\begin{array}{c}\text { Stage-0 } \\
\text { Breast Carcinoma }\end{array}$ & $\begin{array}{c}\text { Stage-I } \\
\text { Breast Car- } \\
\text { cinoma }\end{array}$ & $\begin{array}{c}\text { Stage-II } \\
\text { Breast Carci- } \\
\text { noma }\end{array}$ & $\begin{array}{c}\text { Stage-III Breast } \\
\text { Carcinoma }\end{array}$ & $\begin{array}{c}\text { Stage-IV Breast } \\
\text { Carcinoma }\end{array}$ \\
\hline $\begin{array}{l}\text { Number of } \\
\text { participants }\end{array}$ & 36 & 11 & 6 & 9 & 9 & 3 \\
\hline $\begin{array}{l}\text { Percentage of } \\
\text { participants }\end{array}$ & $48.6 \%$ & $14.9 \%$ & $8.1 \%$ & $12.2 \%$ & $12.2 \%$ & $4 \%$ \\
\hline 25(OH)D & $36.59 \pm 6.78$ & $32.41 \pm 1.38$ & $21.39 \pm 1.24$ & $18.35 \pm 0.83$ & $14.66 \pm 1.03$ & $6.57 \pm 0.61$ \\
\hline
\end{tabular}

Table 2: Comparison of serum Vitamin D between control and various Stages of Breast Carcinoma.

$\mathrm{P}<0.001$ is considered significant.

From table 1, it can be inferred that the mean Vitamin D level in the control group $48.6 \%(\mathrm{n}=36)$ was $36.59 \mathrm{ng} / \mathrm{ml}$ with a standard deviation of 6.78 , which is very much higher than the mean vitamin D level in case group $52.4 \%(\mathrm{n}=38)$ was $21.10 \mathrm{ng} / \mathrm{ml}$ with a standard deviation of 8.25 , which indicates that the level of Vitamin D is found decreased in breast cancer patients.

The results in table 2 shows that Vitamin D levels in various stages of Breast Cancer correlate inversely with increasing stages of Breast Cancer. The Stage-0 Breast Cancer patient had a mean Vitamin D value of $32.41 \mathrm{ng} / \mathrm{ml}$ with a standard deviation of 1.38 . The Stage-I Breast Cancer patient who accounted for $8.1 \%$ of the study population had a mean Vitamin D value of $21.39 \mathrm{ng} / \mathrm{ml}$ with a standard deviation of 1.24. The Stage-II Breast Cancer patient, who accounted for $12.2 \%$ of the study population, had a mean $\mathrm{Vi}$ tamin $\mathrm{D}$ value of $18.35 \mathrm{ng} / \mathrm{ml}$ with a standard deviation of 0.83 . As cancer progressed to higher stages, there was an apparent fall in the Vitamin D levels which was visible with mean Vitamin D levels of $14.46 \mathrm{ng} / \mathrm{ml} \pm 1.03$ and $6.57 \mathrm{ng} / \mathrm{ml} \pm 0.61$ in Stage 3 and Stage 4 , respectively.

\section{Discussion}

The vitamin D receptor is found to be overexpressed in carcinogenic epithelial cells, such as those found in the skin, breast, prostate, and colon, establishing a direct molecular relationship between vitamin D status and carcinogenesis. In epithelial cells, activation of VDR by its ligand 1,25-dihydroxyvitamin D (1,25D) causes extensive genomic alterations that contribute to the maintenance of the differentiated phenotype, tolerance to cellular stressors, and genome protection. Most epithelial cells exhibit the vitamin D metabolizing enzyme CYP27B1, allowing the autocrine synthesis of $1,25 \mathrm{D}$ from the circulating vitamin $\mathrm{D}$ metabolite 25 -hydroxyvitamin D (25D), forming a vital link between overall vitamin D status and cellular anti-tumor effects. Moreover, preclinical research in animal models has shown that vitamin D supplementation or chronic therapy with VDR agonists reduces the growth of tumours in the skin, colon, prostate, and Breast. In mice, however, deletion of the VDR gene create an imbalance between proliferation and apoptosis, increases oxidative DNA damage, and makes these tissues more susceptible to carcinogenesis. Vitamin D status may be a significant regulator of cancer progression in cancer patients be- 
cause VDR expression is preserved in many human malignancies. These findings have highlighted the need to understand further the VDR's molecular functions and the human demand for vitamin D concerning cancer formation and progression [9].

In vitro and animal studies reinforce our findings that vitamin D may protect against breast cancer progression. 1. 25(OH)2D suppresses the metastatic growth of Breast Carcinoma cells, and animals fed different diets show an apparent inverse link between serum levels. Tumorigenesis and 1,25(OH)2D [10]. Vitamin D3 therapy improves intratumoral T-cell immune response and reduces metastasis and locoregional tumour recurrence in a metastatic Lewis tumour model. Breast Carcinoma cell lines are likewise inhibited from proliferating and differentiated by 1,25(OH)2D [11].

Vitamin D decreases the likelihood of large numbers of malignant cells being mobilized into the lymphatic or blood circulation by stimulating the secretion of E-cadherin and catenin, which make cells more adherent to each other, making cells in the tumour mass more adherent to each other, making cells in the tumour mass more adherent to each other, making cells in the tumour mass more adherent to each other, making cells in the tumour mass more adherent to each other, making cells in the tumour Higher 1,25(OH)2D levels may increase the secretion of protein glues, making cancer cells adhere more tightly to the tumour and making the tumour less friable, and decreasing the likelihood of cancer cells dislodging from the tumour tissue during surgery [12].

\section{Conclusion}

From the above study, it can be inferred that the serum vitamin D level can be used as a prognostic marker for various stages of breast cancer patients and vitamin D supplementation might be used in the prevention of breast cancer. Further studies may be extended in the usage of vitamin D/1;25 dihydroxy cholecalciferol to different forms of cancer.

\section{Bibliography}

1. Engan T and Hannisdal E. "Blood analysis as prognostic factor in primary Lung cancer”. Acta Oncology 29 (1990): 151-154.

2. Haugan A. "Women who smoke: an women more susceptible to tobacco induced Lung cancer?" Carcinogenesis 23 (2002): 227-229.
3. Welsh J. "Cellular and molecular effects of vitamin D on carcinogenesis". Archives of Biochemistry and Biophysics 523.1 (2012): 107-114.

4. Wang D., et al. "Serum 25-hydroxyvitamin D and breast cancer".

5. Lappe JM., et al. "Vitamin D and calcium supplementation reduces cancer risk: results of a randomized trial". The American Journal of Clinical Nutrition 85 (2007): 1586-1591.

6. Bauer SR., et al. "Plasma vitamin D levels, menopause, and risk of brast cancer: dose-response meta-analysis of prospective studies". Medicine 92 (2013): 123-131.

7. Goodwin PJ., et al. "Prognostic effects of 25-hydroxyvitamin D levels in early breast cancer". Journal of Clinical Oncology 27 (2009): 3757-3763.

8. Hatse S., et al. "Vitamin D status at breast cancer diagnosis: correlation with tumor characteristics, disease outcome, and genetic determinants of vitamin D insufficiency". Carcinogenesis 33.7 (2012): 1319-1326.

9. Welsh J. "Cellular and molecular effects of vitamin D on carcinogenesis". Archives of Biochemistry and Biophysics 523.1 (2012): 107-114.

10. Moukayed M and Grant WB. "Molecular link between vitamin d and cancer prevention". Nutrients 5 (2013): 3993-4021.

11. Pludowski P., et al. "Vitamin d effects on musculoskeletal health, immunity, autoimmunity, cardiovascular disease, cancer, fertility, pregnancy, dementia and mortality-a review of recent evidence". Autoimmune Review 12 (2013): 976-989.

12. Nakagawa K., et al. "1 alpha,25-dihydroxyvitamin d (3) is a preventive factor in the metastasis of Lung Cancer". Carcinogenesis 26 (2005): 429-440.

\section{Volume 5 Issue 12 December 2021 (c) All rights are reserved by Aananda Krishna KS., et al.}

